\title{
Rabaska
}

Revue d'ethnologie de l'Amérique française

\section{Centre d'études sur la francophonie du Détroit (Université de Windsor)}

\section{Marcel Bénéteau}

Volume 3, 2005

URI : https://id.erudit.org/iderudit/201751ar

DOI : https://doi.org/10.7202/201751ar

Aller au sommaire du numéro

Éditeur(s)

Société québécoise d'ethnologie

ISSN

1703-7433 (imprimé)

1916-7350 (numérique)

Découvrir la revue

Citer ce document

Bénéteau, M. (2005). Centre d'études sur la francophonie du Détroit (Université de Windsor). Rabaska, 3, 220-221. https://doi.org/10.7202/201751ar d'utilisation que vous pouvez consulter en ligne.

https://apropos.erudit.org/fr/usagers/politique-dutilisation/ 


\section{Centre d'études sur la francophonie du Détroit}

Université de Windsor

401, rue Sunset

Windsor, Ontario N9B 3P4

\section{Fermeture}

L'année 2004-2005 a été une année très productive pour le Centre d'études sur la francophonie du Détroit qui, malheureusement, a dû fermer ses portes le 15 mai 2005. Le manque de financement stable de la part de l'Université de Windsor ainsi que le départ du directeur pour un poste en Folklore et ethnologie à l'Université de Sudbury sont les raisons principales de cette fermeture.

\section{Dernières activités}

Le Centre est demeuré actif jusqu'à la fin de son mandat. Nous avons réussi à mener à terme deux collaborations avec la Bibliothèque municipale de Windsor, dirigeant les recherches et contribuant des matériaux de notre collection pour la création de deux sites électroniques. Le premier, « Folklore du Détroit » (www.virtualmuseum.ca/Exhibitions/Folklore/indexF.htm), parrainé par le Musée virtuel du Canada, vise les élèves du primaire, mais s'adresse aussi à quiconque s'intéresse aux traditions orales de la région. Le deuxième site, parrainé par Culture canadienne en ligne, met en valeur un ancien journal français de Windsor (Le Progrès, 1881-1902) et est en voie de devenir une source d'information incontournable pour les recherches sur la langue, l'histoire et la culture des francophones des deux côtés du Détroit (www.windsorpubliclibrary.com/digi/progres/).

Le Centre a complété la préparation du manuscrit Contes $d u$ Détroit, une collection de contes recueillis dans la région de Windsor en 1938 par JosephMédard Carrière. Le recueil sera publié à l'automne 2005 par Prise de Parole, à Sudbury. Le Centre a aussi permis à plusieurs étudiants de l'Université de Windsor de s'initier à l'étude de la francophonie du Détroit. En plus d'avoir travaillé sur les projets de sites pour la toile, des étudiants ont continué le travail de transcription musicale de la collection de chansons traditionnelles françaises et ont aussi participé à la préparation d'un lexique tricentenaire du français du Détroit. Ces derniers travaux se poursuivront maintenant à l'Université de Sudbury. 


\section{Bilan général}

Au cours des quatre dernières années, le Centre d'études sur la francophonie du Détroit, à travers ses colloques, ses publications et ses projets communautaires a réussi à faire connaître et valoir, tant auprès des membres de sa propre communauté que de la communauté scientifique, l'importance du français du Détroit dans l'ensemble de la francophonie nord-américaine. Par exemple, deux projets linguistiques dirigés par France Martineau du département d'Études françaises de l'Université d'Ottawa ont récemment fait appel aux ressources du Centre pour créer un volet sur le français du Détroit (il s'agit du Laboratoire du français familier ancien et du projet « Modéliser le changement : les voies du français », dans le cadre des Grands travaux concertés du

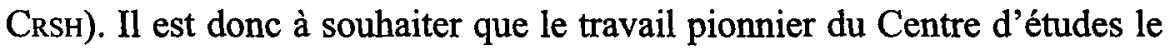
Détroit continuera à alimenter les recherches en plusieurs domaines et à mettre en valeur la culture du premier peuplement français en Ontario.

MARCel BÉNÉTEAU 